\title{
Potencial turístico de la región Huasteca del estado de San Luis Potosí, México
}

\section{Tourist potential of the Huasteca region of San Luis Potosí, Mexico}

\author{
ÓsCar Reyes-PÉrez \\ VAlente VÁzquez-Solís \\ Humberto Reyes-Hernández \\ Miguel Nicolás-Caretta \\ José Guadalupe Rivera-GonZález*
}

\begin{abstract}
Mexico's economic policy in tourism pursues for the year 2012 an annual average increase of $5.7 \%$ in the flow of foreign visitors to its various centers of entertainment and recreation; in other words, 28.9 million international tourists. However, despite the State Government promotes many tourist sites, there is a lack of sufficient studies to assess their ability to meet the demand they are expecting to capture. This paper develops a methodology that determines the tourist potential of the Huasteca Potosina based on the natural-cultural touristic resources, tourist equipment and accessibility; it also reveals that area of study, in spite of having an important basic offer, lacks supplementary supply to secure a more dynamic tourism.
\end{abstract}

Keywords: geography of the tourism, tourist potential, cultural heritage, Huasteca Potosina.

\section{Resumen}

La política económica de México en materia de turismo planea para 2012 un incremento promedio anual de $5.7 \%$ del flujo de visitantes extranjeros a sus diversos centros de ocio y recreación; es decir, 28.9 millones de turistas internacionales. Sin embargo, aunque el gobierno del estado promueve múltiples sitios turísticos, no cuenta con estudios suficientes que evalúen su capacidad para atender la demanda que se espera captar. El presente trabajo, con base en los recursos naturales-culturales, la infraestructura y el acceso desarrolla una metodología que determina el potencial turístico de la Huasteca Potosina; revela además que la zona de estudio, si bien posee una importante oferta básica, carece de la oferta complementaria que asegure un turismo más dinámico.

Palabras clave: geografía del turismo, potencial turístico, patrimonio cultural, Huasteca Potosina.

* Universidad Autónoma de San Luis Potosí, México. Correos-e: osrp@uaslp.mx, vazquezsv@ uaslp.mx, hreyes@uaslp.mx, ncaretta@uaslp.mx, joserivera@uaslp.mx. 


\section{Introducción}

En México, la actual política económica del gobierno federal se sustenta en la competitividad, la eficiencia y la generación de empleos en los sectores que se consideran estratégicos. En este sentido, uno de los ejes prioritarios para la acción pública corresponde al sector turístico por ser uno de los que más ingresos económicos aportan al país por concepto de divisas. Esto se refleja de manera sustancial en el Programa Sectorial de Turismo 2007-2012, documento rector que pretende articular los esfuerzos para hacer de éste "una actividad estratégica e integrada a la vida económica, social, cultural y política del país, capaz de atender de forma competitiva una amplia gama de segmentos de mercado nacional e internacional, sin detrimento de la calidad del patrimonio natural y cultural" (Sectur, 2007: 28).

Para lograrlo, se estableció como objetivo central incrementar el flujo de visitantes extranjeros hacia los centros de recreación nacionales a una tasa promedio anual de $5.7 \%$. A este ritmo, se alcanzaría la cifra de 28.9 millones de turistas internacionales al final de este periodo, 30\% superior al actual, que se suma a los de 166 millones de turistas mexicanos que se estiman para entonces (Sectur, 2007: 23). Si estas expectativas se cumplen, las divisas obtenidas por quienes se trasladan a algún lugar de la República Mexicana por motivos de ocio, diversión, descanso, salud, negocios, visitas a familiares o amigos, religión, eventos sociales o compras, entre otros, aumentarían 16,059 millones de dólares. El 79.1\% de estos ingresos provendría de los turistas extranjeros o mexicanos -residentes en el exterior- que se internan en el territorio nacional (turismo de internación); mientras que el $20.9 \%$ se originaría por el desplazamiento temporal de personas fuera de su lugar de residencia habitual hacia las ciudades contiguas a la línea divisoria con México (turismo fronterizo). En consecuencia, existirían los incentivos necesarios para que la iniciativa privada invirtiera más de 20,000 millones de dólares y se generaran 125,000 empleos durante este periodo (Sectur, 2007: 23).

El cálculo de la inversión de la iniciativa privada se previó con la finalidad de lograr la equidad interregional de los estados federativos, al incentivar el turismo sobre todo en aquéllos donde el nivel de pobreza patrimonial es más de $10 \%$ superior al promedio nacional; de forma que Guerrero, Chiapas, Durango, Tabasco, Veracruz, Puebla, Oaxaca y San Luis Potosí se convirtieron en territorios prioritarios para la inversión turística a partir de 2007.

Sin embargo, en tales proyecciones no se consideró con suficiencia los factores que hacen del turismo una actividad con un elevado nivel de aleatoriedad. Por ejemplo, numerosos destinos turísticos en el mundo, al 
iniciar el decenio de los noventa del siglo xx, por el cambio climático han sido susceptibles a una incidencia significativa en la frecuencia e intensidad de los eventos hidrometeorológicos que interrumpen esta actividad. En el caso de México, se han presentado de forma recurrente y han ocasionado cuantiosas pérdidas humanas y económicas. En las condiciones descritas, existe un panorama difícil y de incertidumbre económica para los centros geográficos que basan su desarrollo en el turismo (Vázquez y Benito, 2009).

Asimismo, factores como las modas, los conflictos políticos, el narcotráfico, la seguridad pública, entre otros, y que cambian en el corto y mediano plazos hacen que los sitios orientados preferentemente al sector turístico incrementen sus condiciones de vulnerabilidad. A este respecto, en 2009 México, ante la alerta epidemiológica que emitió la Organización Mundial de la Salud ante un brote de influenza humana (AH1N1) en todo su territorio, vio afectada su imagen turística en el mercado internacional (Sectur, 2009).

De forma particular, los íconos de turismo litoral -entre los que destacan Cancún, Cozumel, Ixtapa-Zihuatanejo, Puerto Vallarta y Acapulco- experimentaron una recesión aún mayor de los efectos que se suscitaron en otros lugares. En consecuencia, el gobierno mexicano constituyó un primer fondo de 200 millones de pesos, en un esquema de paripaso con las entidades federativas para la promoción turística en el mercado nacional y, en su oportunidad, en el internacional. Además, estableció una bolsa con recursos de las secretarías de Hacienda y de Turismo, así como del Consejo de Promoción Turística de México (СРТM), por un monto de mil millones de pesos adicionales para reposicionar la imagen de México mediante campañas de promoción nacional e internacional y estrategias de relaciones públicas (Gobierno Federal, 2009). Así, la diferencia en la captación de divisas -tras haber llegado a una contracción de $49 \%$ en el mes de mayo por el brote de influenza- a finales de 2009 con respecto a los niveles del mismo mes del año anterior fue sólo $4.5 \%$ menor, siendo ésta la diferencia más baja desde la caída del mes de mayo (Sectur, 2010).

En estas condiciones, el apoyo del turismo en aquellos sitios donde debe complementar, nunca supeditar, como actividad preponderante del desarrollo socioeconómico regional, tiene que estar apoyado en estrategias alternativas, coherentes y oportunas que operen de manera eficiente a fin de prevenir los efectos territoriales negativos que se suscitan cuando los factores aleatorios lo convierten en una actividad vulnerable. Entre esos espacios se ubica el estado de San Luis Potosí, y en particular la región Huasteca que no está preparada para el crecimiento sostenido del turismo, ya que no cuenta, en general, con una infraestructura adecuada para este 
caso, y porque no existen suficientes estudios multidisciplinarios que identifiquen su patrimonio natural y cultural que antecedan o acompañen cualquier estrategia de inversión o instrumentación de planes de operación en el sector.

\section{Contexto geográfico de la Huasteca Potosina}

Situada en el extremo oriental del estado de San Luis Potosí, la Huasteca Potosina constituye, desde el punto de vista socioeconómico, la segunda región más importante de esta entidad federativa. De hecho, por su posición geográfica excepcional, en el límite convergente de la región neotropical y neártica, cuenta con una diversidad paisajística y de recursos naturales aptos para el aprovechamiento con fines de ocio y recreación (Castañeda, 2010: 57-80). De forma similar, al hallarse en lo que históricamente se ha considerado el área de transición de Mesoamérica y Aridoamérica, posee zonas prehispánicas que se constituyen como elementos fundamentales del patrimonio cultural en esta parte del territorio nacional, tal es el caso de los sitios de Tamtoc y Tamohí, ubicados en el municipio de Tamuin (Castañeda, 2010: 116; Stresser, 2010) (mapa I).

A continuación examinamos con más detalle particularidades naturales y culturales de esta región.

\subsection{Rasgos relevantes del componente natural de la Huasteca Potosina}

En lo que se refiere al aspecto fisiográfico, la zona de estudio está enmarcada por tres subprovincias: Llanuras y Lomerios, Carso Huasteco y Gran Sierra Plegada (Castañeda, 2010: 62). La primera se caracteriza por un relieve plano que consiste en un sistema de topoformas de lomeríos, llanuras y valles, con ligera inclinación hacia la costa del Golfo de México; sus máximas elevaciones son de 150 metros y las mínimas de 15 metros; los materiales más comunes son sedimentos antiguos, arcillosos o arenosos y afloramientos de rocas basálticas. La segunda se constituye principalmente por sierras y en menor proporción por cañones, valles y llanuras; que al contar con un predominio de rocas calcáreas, solubles en agua, han generado grutas, pozos y dolinas. La tercera se asocia con una morfología de estratos plegados en forma de mesetas, valles intermontanos y lomeríos, donde las cumbres llegan a exceder los 1,000 msnm; además tiene un sistema de fallas con orientación norte-sur y dominancia de rocas calizas marinas con rasgos de carsificación (INEGI, 2002a: 18-20).

Con respecto a los climas, en la Huasteca Potosina hay nueve tipos que pertenecen a los cálidos, semicálidos y templados, con una prepon- 


\section{Mapa I \\ Oferta turística de la región Huasteca Potosina}

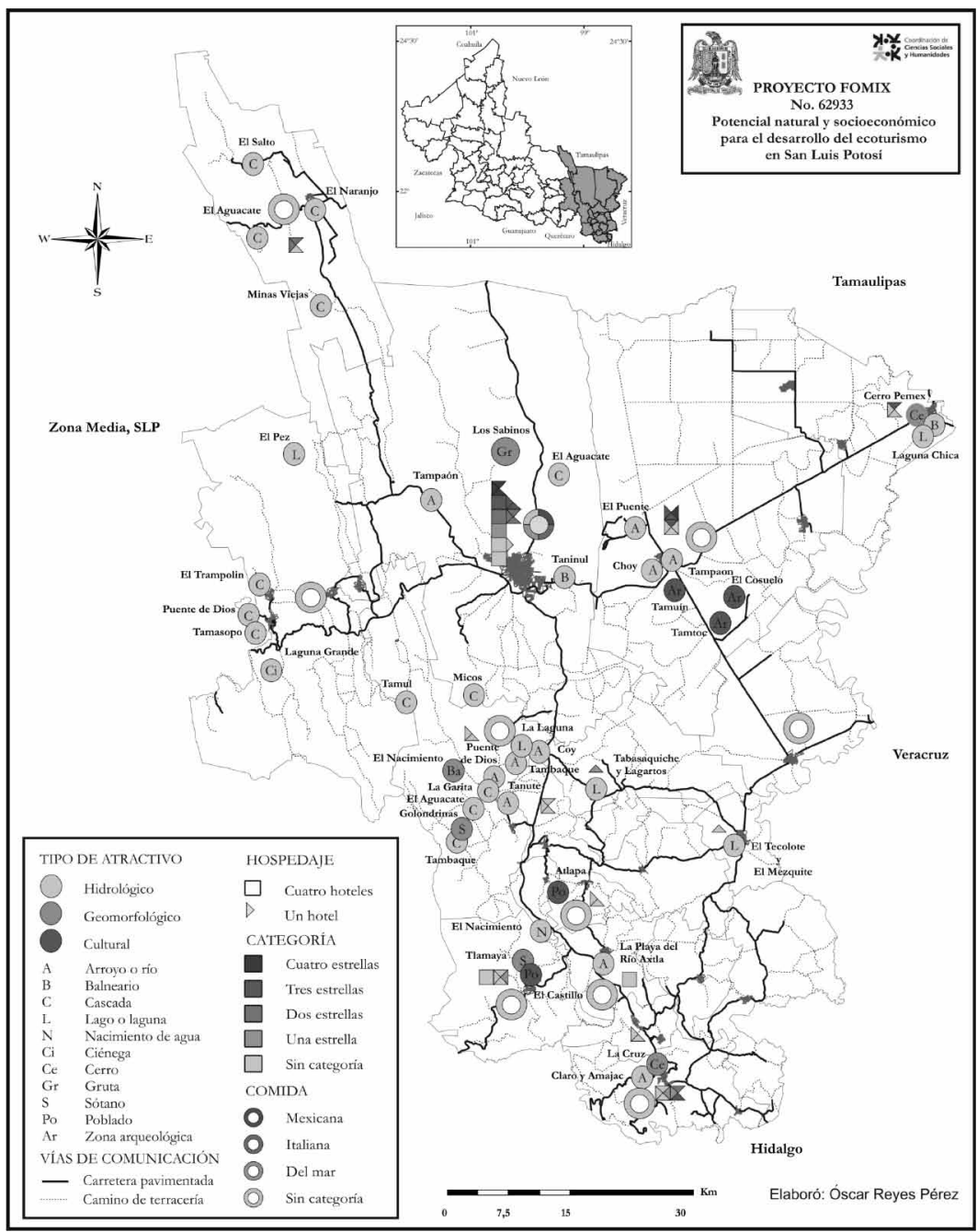

Fuente: INEGI, 2006 y trabajo de campo, 2008.

derancia de los dos primeros. Hacia el noreste de la región se pueden identificar cuatro subtipos denominados cálidos subhúmedos con lluvias en verano, donde las temperaturas medias anuales son superiores a los $22^{\circ} \mathrm{C}$, con precipitaciones totales anuales que rebasan los $800 \mathrm{~mm}$ en la zona localizada hacia el declive del Golfo de México y superiores a 1,800 $\mathrm{mm}$ en las estribaciones de la Sierra Madre Oriental. Por otra parte, con una franja cuya orientación va del noroeste al sur de la región, se distri- 
buyen los climas semicálidos, tanto los que tienen lluvias todo el año, los que cuentan con abundantes lluvias en verano, así como los subhúmedos con lluvias en verano; en estas variantes climáticas las temperaturas medias anuales se ubican entre los $18^{\circ}$ y $24^{\circ} \mathrm{C}$, pero con una diferencia significativa entre las mismas en cuanto a la precipitación anual, pues los registros son de 1,200 a 2,500 mm en el caso de la primera, de 1,200 a $3,500 \mathrm{~mm}$ en la segunda y de 800 a $1,200 \mathrm{~mm}$ para la tercera. Por último, en una pequeña porción del sur de la Huasteca Potosina, en sus límites con el estado de Querétaro, se hallan dos climas templados, los que tienen abundantes lluvias en verano y los subhúmedos con lluvias en verano; en ambos la temperatura media anual se coloca entre $12^{\circ}$ y $18^{\circ} \mathrm{C}$; con la salvedad de que el primero tiene una precipitación media anual de 1,000 a $2,500 \mathrm{~mm}$, mientras que para el segundo no rebasa los 1,500 mm (INEGI, 2002a: 28-32).

En relación con la hidrografía, la zona de estudio se halla en la región hidrológica del Bajo Pánuco, que posee significativas corrientes debido a la amplia red fluvial que confluye hacia ella. De hecho, esta región se integra por cuatro cuencas cuyas características principales son: 1) cuenca del río Pánuco, cuenta con ríos intermitentes que vierten sus aguas en los lagos Chagil y Cerro de la Pez, que con un rango de escurrimiento de 100 a $200 \mathrm{~mm}$ se aprovecha para regar una porción de los cultivos del distrito 92 Ánimas-Chicayán Pujal Coy; 2) cuenca del río Tamesí, con una serie de afluentes del río Tantoan, de régimen perenne, su escurrimiento se eleva hasta $500 \mathrm{~mm}$, por lo que se utiliza para complementar el riego del distrito referido; 3) cuenca del río Tamuín, es la que más aguas superficiales aporta tanto a la Huasteca como al estado pues llega a contar, en algunos lugares, con el doble del volumen de precipitaciones pluviales con respecto a las dos cuencas anteriores, en ésta sobresalen los ríos $\mathrm{Ga}-$ llinas, Tamasopo y Valles, su nivel de escurrimiento también asciende a $500 \mathrm{~mm}$ y se utiliza para fines agrícolas y de abasto de agua potable, y 4) cuenca del río Moctezuma, con dos ríos importantes que son el Axtla y San Pedro, posee elementos similares a las anteriores, pero en este caso adquiere relevancia porque tiene altos índices de contaminación por aguas residuales y desechos industriales provenientes de los centros urbanos circunscritos (INEGI, 2002a: 50-51).

\subsection{Generalidades histórico-culturales en la Huasteca Potosina}

El patrimonio cultural de la Huasteca Potosina que se utiliza preferentemente para la promoción de la actividad turística corresponde a vestigios prehispánicos y coloniales; así como de algunos eventos ocurridos durante los siglos XIX y xx. 
En relación con el mundo precolombino, si bien en la región hay evidencia de que los primeros pobladores se remontan a la etapa lítica, su acervo cultural por excelencia consiste en las aportaciones hechas por los huastecos que, desde una antropología física y lingüística, tuvieron un nexo indiscutible con pueblos mayas durante el periodo Preclásico mesoamericano, pero cuando se alejaron desarrollaron sus propias estructuras culturales; tal es el caso del centro urbano de Tamtok que ocho siglos a.C. alcanzó su máximo esplendor, y el de Tamohi, construido tres siglos antes de la conquista española (Stresser, 2010).

A principios del siglo $\mathrm{xv}$, dentro del área de influencia de la cultura huasteca, se consolidaron los asentamientos de población de Tamuín y Xilitla, que para la segunda mitad de ese siglo quedaron bajo el control de la Triple Alianza, o Excan Tlatoloyan, que fue la última confederación de Estados indígenas del valle de México, durante el periodo Posclásico mesoamericano. Para 1520, estas dos localidades sobresalían por su privilegiada ubicación estratégica como puntos de control comercial en el área Huasteca independiente; en cuanto a los poblados de Oxitipan, Chalchicuautla y Tamazunchale, desempeñaron un papel complementario (Garza y Jiménez, 2007; Garza et al., 2007). Posteriormente, entre 1531 y 1533, durante el segundo periodo de expediciones y conquistas, y en plena fase de contacto y confrontación cultural entre señoríos indígenas y españoles, la localidad de Valles (actualmente Ciudad Valles) se integró al proceso de poblamiento español al formar parte de la ruta conocida como Camino al Este (Paredes, 2007).

En cuanto a los orígenes del sincretismo religioso que actualmente caracteriza a la población indígena de la Huasteca Potosina, como en el caso de los pueblos teenek, se remontan al ańo 1543, cuando la zona correspondiente a Xilitla fue evangelizada por la orden religiosa de los agustinos (Jiménez, 2007).

Ahora bien, durante el siglo xvi la Huasteca quedó al margen de la integración económica debido a que era un espacio disfuncional, desarticulado y aislado del resto de la Nueva España (Olmos y Roque, 2007). Y fue hasta el siglo XviII cuando se caracterizó como uno de los principales centros agropecuarios de la Nueva Espańa; aunque mantuvo una mala disposición de sus redes de intercambio económico y político (Moyado, 2007; Olmos y Roque, 2007b).

En relación con los territorios que ahora no cuentan con una presencia significativa de población indígena, esta situación se remonta a finales del siglo XviII, en particular en la localidad de Los Valles, que al convertirse en punto de enlace entre Pachuca y Santander, lo hizo con base en un crecimiento demográfico de habitantes no indios (Olmos, 2007; Pinzón y Trejo, 2007). 
Posteriormente, durante la segunda mitad del siglo XIX y la primera del $\mathrm{xx}$, en esta porción del territorio potosino destacaron tres acontecimientos económicos, políticos y militares. El primero ocurrió en 1876, cuando Ciudad Maíz se integró a un sistema de transporte hacia Ciudad Victoria y Tampico, en el estado de Tamaulipas (Angulo et al., 2007); el segundo se presentó entre 1916 y 1920, cuando en ella se refugiaron ejércitos rebeldes cedillistas; el tercero correspondió al periodo de 1935 a 1937, al ser el escenario de combates contra grupos armados sin filiación ideológica (Cruz y Trejo, 2007).

Como se puede deducir de los dos apartados anteriores, en la zona de estudio existen condiciones físico-geográficas propicias y un importante legado cultural que hacen factible el desarrollo de la actividad turística (mapa I).

\section{Consideraciones metodológicas}

El procedimiento metodológico para describir la base natural y cultural de un territorio determinado, la evaluación del mismo para el desarrollo de la actividad turística, la ponderación del equipamiento y los servicios turísticos disponibles, así como la determinación del potencial turístico, se encuentra referido de forma parcial o total en los trabajos de Leno (1993: 820-876), López (1998: 155-188; 2009: 93-96), Reyes y Sánchez (2005: 155-169), Reyes (2006: 150-169) y Vázquez et al. (2010: 235237). En el presente trabajo se sintetiza de la forma siguiente.

A partir de la consideración de que tanto los elementos naturales como los culturales son significativos para el desarrollo de la actividad turística en la zona de estudio, se procedió a elaborar un inventario de sus atractivos a través de la información puntual que se recabó en diversas fuentes documentales, cartográficas y de Internet.

Para establecer qué elementos constituyen el patrimonio turístico de la zona de estudio se tomó como referencia las clasificaciones utilizadas por instituciones de México (Sectur, 2010b) y del extranjero (MCD, 2004; Mincetur, 2006). Así, en este trabajo el inventario se conformó mediante la identificación tanto de atractivos naturales como geológico-geomorfológicos, hidrológicos y áreas especiales; mientras que para los culturales se consideraron los componentes arquitectónicos, arqueológicos, haciendas, expresiones culturales relacionadas con los grupos indígenas, tradiciones, fiestas y celebraciones religiosas (cuadro 1).

Es importante mencionar que el procedimiento se realizó para los 58 municipios que integran el estado de San Luis Potosí; esto tuvo como finalidad que la cartografía derivada revelara diferencias del potencial turístico de la zona de estudio con respecto a toda la entidad. 


\section{Cuadro 1}

Elementos considerados para el inventario del patrimonio turístico

\begin{tabular}{|c|c|c|c|}
\hline \multicolumn{4}{|c|}{ Atractivos turisticos } \\
\hline \multicolumn{2}{|c|}{ Naturales } & \multicolumn{2}{|c|}{ Culturales } \\
\hline $\begin{array}{l}\text { 1. Oquedades (caver- } \\
\text { nas, grutas, sótanos } \\
\text { y cuevas) } \\
\text { 2. Monolitos (cornisas, } \\
\text { crestas, bufas, aretes, } \\
\text { agujas, cuellos) } \\
\text { 3. Rocas sobrepuestas } \\
\text { (piedras, encimadas, } \\
\text { en equilibrio, pirá- } \\
\text { mides de hadas). } \\
\text { 4. Volcanes y montañas } \\
\text { 5. Valles intermon- } \\
\text { tanos } \\
\text { 6. Cañones (barrancos, } \\
\text { cańadas, gargantas } \\
\text { y desfiladeros) }\end{array}$ & $\begin{array}{l}\text { 7. Cascadas (caídas } \\
\text { de agua, saltos, } \\
\text { chorreras, } \\
\text { chorreaderos) } \\
\text { 8. Lagos y lagunas } \\
\text { continentales } \\
\text { 9. Balnearios } \\
\text { 10. Represamientos } \\
\text { (presas y bordos) } \\
\text { 11. Manantiales } \\
\text { (fríos, hipo, meso) } \\
\text { 12. Corrientes super- } \\
\text { ficiales (ríos } \\
\text { y arroyos) } \\
\text { 13. Reservas de la } \\
\text { biosfera* } \\
\text { 14. Parques } \\
\text { municipales } \\
\text { 15. Miradores }\end{array}$ & $\begin{array}{l}\text { 1. Museos } \\
\text { 2. Teatros } \\
\text { 3. Bibliotecas } \\
\text { 4. Fototecas } \\
\text { 5. Casas de arte } \\
\text { 6. Galerías } \\
\text { 7. Auditorios } \\
\text { 8. Catedrales } \\
\text { 9. Monumentos } \\
\text { 10. Parroquias } \\
\text { 11. Capillas } \\
\text { 12. Santuarios } \\
\text { 13. Templos } \\
\text { 14. Sitios arqueoló- } \\
\text { gicos (Preclá- } \\
\text { sico, Clásico } \\
\text { y Posclásico) } \\
\text { 15. Centros } \\
\text { comunitarios }\end{array}$ & $\begin{array}{l}\text { 16. Haciendas } \\
\text { (siglos XVI, XVII, } \\
\text { XVIII y XIX, SD) } \\
\text { 17. Celebraciones } \\
\text { de Semana } \\
\text { Santa y Día } \\
\text { de Muertos } \\
\text { 18. Fiestas } \\
\text { 19. Festivales } \\
\text { 20. Ferias } \\
\text { 21. Rituales } \\
\text { 22. Expresiones } \\
\text { culturales rela- } \\
\text { cionadas con } \\
\text { los grupos } \\
\text { indígenas } \\
\text { 23. Centros de } \\
\text { desarrollo } \\
\text { indígena }\end{array}$ \\
\hline
\end{tabular}

* Un elemento fundamental para determinar el potencial turístico de un territorio es la riqueza paisajística que ofrecen las asociaciones vegetales. En este trabajo fue evidente que, en lo que atañe a la región Huasteca Potosina, todos los municipios se caracterizan porque cuentan con varios tipos de vegetación; por lo que se reemplazó esta variable por la de Reservas de la Biosfera al constituirse como las áreas que contienen los índices más altos de biodiversidad.

Fuente: Elaboración propia con base en Sectur, 2010b; MCD, 2004; Mincetur, 2006.

Una vez que se contó con el inventario, se procedió a establecer una relación cuantitativa entre los recursos turísticos con la infraestructura que atiende las necesidades de los visitantes. En tal sentido, en este trabajo se analizaron aquellas variables mensurables (naturales, de equipamientos y de accesibilidad) que permitieron evaluar las condiciones del patrimonio y de los servicios turísticos de la región de la Huasteca. Para tal efecto, como se mencionó, se recogió la experiencia de Reyes y Sánchez (2005: 155-169), López (1998: 155-188) y Leno (1993: 820-876). La metodología que utilizaron estos autores considera en primer lugar lo siguiente: 1) la jerarquización de los recursos seleccionados; 2) el establecimiento de un factor de ponderación, de acuerdo con la categoría en que está integrado el recurso, y 3) la elaboración final del índice de valor turístico (IVT) de todos los recursos y, por ańadidura, de cada unidad territorial.

Para establecer en una escala ordinal cinco jerarquías de recursos se consideró el método de jerarquización de la Organización de Estados Americanos (oEA), modificado por Álvarez y Leno (1986): 
- Jerarquía 1: recursos con poco o nulo interés

- Jerarquía 2: interés local

- Jerarquía 3: interés regional

- Jerarquía 4: interés nacional

- Jerarquía 5: interés internacional

A partir de estas consideraciones, para el caso que aquí se examina, las jerarquías correspondientes para los atractivos naturales y culturales se especifican en los cuadros 2 y 3.

\section{Cuadro 2}

\section{Jerarquías del patrimonio natural}

\begin{tabular}{ll}
\hline Jerarquía & \multicolumn{1}{c}{ Categoría: geológico-geomorfológicos, hidrológicos y áreas especiales } \\
\hline 1 & Cañones (barrancos, cańadas, gargantas y desfiladeros) \\
& Corrientes superficiales (ríos y arroyos) \\
& Valles intermontanos \\
& Manantiales (fríos, hipo, meso) \\
3 & Volcanes y montańas \\
& Represamientos (presas y bordos) \\
& Miradores \\
& Monolitos (cornisas, crestas, bufas, aretes, agujas, cuellos) \\
& Rocas sobrepuestas (piedras encimadas, en equilibrio, pirámides de hadas) \\
& Parques municipales \\
& Oquedades (cavernas, grutas, sótanos y cuevas) \\
& Cascadas (caídas de agua, saltos, chorreras, chorreaderos) \\
& Lagos y lagunas continentales \\
& Reservas de la biosfera
\end{tabular}

Fuente: Elaboración propia.

\section{Cuadro 3}

\section{Jerarquías del patrimonio cultural}

\begin{tabular}{ll}
\hline Jerarquía & $\begin{array}{l}\text { Categoría: arquitectónicos, arqueológicos, haciendas, grupos étnicos, tradicio- } \\
\text { nes, fiestas y celebraciones religiosas }\end{array}$ \\
\hline 1 & Rituales, estatuas y bibliotecas \\
2 & Centros de desarrollo indígena, fototecas y haciendas (sin registro) \\
3 & Auditorios, monumentos y ferias \\
4 & Casas de arte, galerías, centros comunitarios, templos, parroquias, capillas, \\
& santuarios, haciendas (siglos XVI, XVII, XVIII y XIX), celebraciones de Sema- \\
& na Santa y Día de Muertos \\
5 & Sitios arqueológicos (Preclásico, Clásico y Posclásico), museos, teatros, ca- \\
& tedrales y expresiones culturales relacionadas con los grupos indígenas
\end{tabular}


Es importante mencionar que si bien las jerarquías de la escala ordinal fueron formuladas con base en los criterios establecidos por las instituciones oficiales referidas, los elementos que las constituyen parten del criterio de los investigadores sobre lo que desean destacar. Por otra parte, en cuanto al significado turístico de cada jerarquía, Leno menciona que

La jerarquía del recurso no indica el valor turístico de éste sino simplemente su importancia dentro de su propia categoría en función de criterios totalmente ajenos a su aprovechamiento turístico (interés artístico, singularidad o espectacularidad, etc.). La transformación de esta jerarquía en una evaluación con fines turísticos ha sido resuelta generalmente mediante el establecimiento de factores de ponderación, no para cada recurso en particular sino para grandes conjuntos de recursos agrupados según su naturaleza (1993: 827).

Así, el factor de ponderación elegido para este caso, con sus modificaciones pertinentes para San Luis Potosí, parte de Ferrario (1980, referido en Leno, 1993) en su evaluación de los recursos turísticos sudafricanos; de Cinelli (1980, referido en Leno, 1993) al aplicar la misma metodología en una provincia italiana y del trabajo de López (1998) consistente en la ordenación y planificación de los recursos territoriales turísticos del Alto Palancia. En consecuencia, los coeficientes de ponderación para las categorías de recursos turísticos elegidos suman en total 1 (cuadro 4), y son los siguientes:

\section{Cuadro 4 \\ Factores de ponderación}

\begin{tabular}{lcll}
\hline \multicolumn{1}{c}{ Naturales } & \multicolumn{2}{c}{ Culturales } \\
\hline Geológico-geomorfológicos & 0.4 & Arqueológicos y haciendas & 0.4 \\
Hidrológicos & 0.4 & Arquitectónicos & 0.3 \\
Áreas especiales & 0.2 & Manifestaciones culturales & 0.2 \\
& & Servicios culturales & 0.1 \\
Total & 1.0 & & 1.0 \\
\hline
\end{tabular}

Fuente: Elaboración propia.

Asimismo, de acuerdo con la recomendación de Leno (1993), se sumó una constante $\mathrm{K}=1$ a cada elemento (cuadro 5).

\section{Cuadro 5 \\ Derivación de los factores de ponderación}

\begin{tabular}{llll}
\hline \multicolumn{1}{c}{ Naturales } & \multicolumn{2}{c}{ Culturales } \\
\hline Geológico-geomorfológicos & 1.4 & Arqueológicos y haciendas & 1.4 \\
Hidrológicos & 1.4 & Arquitectónicos & 1.3 \\
Áreas especiales & 1.2 & Manifestaciones culturales & 1.2 \\
& & Servicios culturales & 1.1 \\
\hline
\end{tabular}

Fuente: Elaboración propia. 
Una vez que se determinaron estos parámetros, para cada municipio se obtuvo el índice de valor turístico de sus componentes natural y cultural. Para ello, en primer lugar se multiplicó cada elemento de su patrimonio turístico con su correspondiente jerarquía y por el factor de ponderación derivado; después, se obtuvo el puntaje total (Cuadro 6).

\section{Cuadro 6 \\ Índice del patrimonio turístico de los municipios de la región Huasteca Potosina}

\begin{tabular}{lrc}
\hline \multicolumn{1}{c}{ Municipio } & \multicolumn{2}{c}{ Índice turístico } \\
& Natural & Cultural \\
\hline Aquismón & 40.6 & 38.6 \\
Matlapa & 4.2 & 67.1 \\
Tancanhuitz & 12.6 & 41.5 \\
Ciudad Valles & 22.4 & 95.4 \\
Coxcatlán & 0 & 25.4 \\
Ébano & 18.2 & 23.0 \\
Huehuetlán & 16.8 & 35.7 \\
San Antonio & 0 & 37.2 \\
San Martín Chalchicuautla & 5.6 & 41.3 \\
San Vicente Tancuayalab & 0 & 48.6 \\
Tamasopo & 28.8 & 34.3 \\
Tamazunchale & 5.6 & 76.1 \\
Tampacan & 0 & 25.6 \\
Tampomolón Corona & 0 & 55.7 \\
Tamuín & 8.4 & 42.2 \\
Tanlajás & 15.4 & 22.6 \\
Tanquián de Escobedo & 14.0 & 24.4 \\
Axtla de Terrazas & 8.4 & 15.7 \\
Xilitla & 6.2 & 51.0 \\
El Naranjo & 11.2 & 9.0 \\
\hline
\end{tabular}

Fuente: Elaboración propia.

Para ponderar el equipamiento turístico, en primer lugar se recabó información que proporciona el Instituto Nacional de Geografía, Estadística e Informática (INEGI) en lo referente a hoteles, establecimientos de alimentos y de bebidas, agencias de viajes y arrendadoras de autos. Después, los datos se diferenciaron en tres grupos que a su vez se jerarquizaron como se muestra en el cuadro 7. 


\section{Cuadro 7 \\ Jerarquías del equipamiento turístico}

\begin{tabular}{|c|c|c|c|}
\hline Jerarquia & Hoteles & $\begin{array}{c}\text { Establecimientos de bebidas } \\
y \text { alimentos }\end{array}$ & $\begin{array}{l}\text { Agencias de viajes y } \\
\text { arrendadoras de autos }\end{array}$ \\
\hline 1 & Una estrella & Sin categoría & \\
\hline 2 & Dos estrellas & Con comida rápida & Sólo se consideró la \\
\hline 3 & Tres estrellas & Con comida del mar & jerarquía 5 \\
\hline 4 & Cuatro estrellas & Con comida mexicana & \\
\hline 5 & Cinco estrellas & Con comida internacional & Con establecimientos \\
\hline
\end{tabular}

Fuente: Elaboración propia.

Las jerarquías se concibieron en función de la rentabilidad que representa cada elemento en el desarrollo de la actividad turística; así, un lugar cuyo equipamiento ${ }^{1}$ contenga hoteles de cinco estrellas, establecimientos con un arte culinario de carácter nacional e internacional y que además ofrezca al visitante opciones para recorrer el territorio, evidencia un turismo más consolidado que aquéllos donde es mayor la infraestructura propia de las jerarquías de menor nivel.

Una vez que se establecieron las jerarquías para cada tipo de equipamiento turístico, se determinó un factor de ponderación con base en la relevancia que representa cada uno de ellos para el funcionamiento de la actividad turística. A este respecto, se le dio un valor de tres puntos a los hoteles, dos a los establecimientos de bebidas y comida, y de uno a las agencias de viajes y arrendadoras de autos. De forma que si un municipio tiene un hotel de cinco estrellas, se le da un puntaje de 15 unidades; si dispone además de un establecimiento de comida mexicana, se le agregan ocho puntos; y si cuenta además con una agencia de viajes, entonces aumentaría otros cinco puntos. Con esa lógica se determinó el índice de equipamiento turístico (cuadro 8).

En el caso de la accesibilidad se consideró el indicador referente con la suficiencia vial (índice de Engel) porque

En el actual contexto de los espacios o redes de flujos se distingue, por supuesto, la organización y funcionalidad de los principales corredores para el tráfico de pasajeros y mercancías y los vínculos urbano-regionales entre distintos territorios. Incluso la ubicación de terminales de transporte constituye un factor determinante en la estructuración de las regiones directamente vinculadas con ellas y, con mayor énfasis, con sus áreas adyacentes. Este indicador representa, en consecuencia, la capacidad que tiene la red vial de cada municipio para garantizar los ser-

\footnotetext{
${ }^{1}$ Las relaciones no siempre son lineales, pues el equipamiento de un lugar puede estar integrado por elementos de todas las categorías; al final, la diferencia estriba en la suma total de los valores asignados a cada jerarquía que posea ese lugar con respecto a la de otro.
} 
vicios de transporte, considerando la población y la superficie de cada unidad territorial analizada (Palacio et al., 2004).

El índice se puede calcular con la siguiente fórmula:

$$
I e=\frac{K m V_{-}^{*} 100}{\operatorname{Rai}^{2}\left(S^{*} P\right)}
$$

Donde: $I e=$ índice de Engel; $K m V=$ longitud en kilómetros de las carreteras y vías férreas de la entidad; $S=$ kilómetros cuadrados de superficie municipal; $P=$ número de habitantes.

Así se obtuvieron los índices de equipamiento y suficiencia vial para cada municipio de la región Huasteca del estado de San Luis Potosí (cuadro 8).

\section{Cuadro 8 \\ Índice de equipamiento turístico y de accesibilidad de los municipios de la región Huasteca Potosina}

\begin{tabular}{lcc}
\hline \multicolumn{1}{c}{ Municipio } & \multicolumn{2}{c}{ Indice turístico } \\
& Equipamiento & Accesibilidad \\
\hline Aquismón & 4 & 4.9 \\
Matlapa & 9 & 10.8 \\
Tancanhuitz & 237 & 8.6 \\
Ciudad Valles & 8 & 2.7 \\
Coxcatlán & 15 & 13.3 \\
Ébano & 0 & 2.7 \\
Huehuetlán & 0 & 10.3 \\
San Antonio & 0 & 7.1 \\
San Martín Chalchicuautla & 2 & 7.0 \\
San Vicente Tancuayalab & 41 & 10.9 \\
Tamasopo & 32 & 3.9 \\
Tamazunchale & 0 & 8.7 \\
Tampacan & 0 & 8.4 \\
Tampomolón Corona & 30 & 9.1 \\
Tamuín & 3 & 3.8 \\
Tanlajás & 3 & 5.1 \\
Tanquián de Escobedo & 14 & 8.3 \\
Axtla de Terrazas & 32 & 8.1 \\
Xilitla & 22 & 6.8 \\
El Naranjo & & 3.7 \\
\hline
\end{tabular}

Fuente: Elaboración propia y trabajo de campo, 2008 


\section{Cuadro 9}

\section{Ponderación cualitativa y cuantitativa de los elementos seleccionados}

\begin{tabular}{|c|c|c|c|c|c|}
\hline \multirow{2}{*}{\multicolumn{2}{|c|}{$\begin{array}{l}\text { Jerarquias } \\
\text { cualitativas }\end{array}$}} & \multicolumn{4}{|c|}{$\begin{array}{c}\text { Rangos cuantitativos } \\
\text { (indices) }\end{array}$} \\
\hline & & Natural & Cultural & Equipamiento & Accesibilidad \\
\hline Muy bajo & 1 & 0 & $<26.0$ & 0 & $<2.5$ \\
\hline Bajo & 2 & $3.0-15.9$ & $26.0-49.9$ & $2-40$ & $2.6-3.9$ \\
\hline Medio & 3 & $16.0-22.9$ & $50.0-99.9$ & $41-100$ & $4.0-7.9$ \\
\hline Alto & 4 & $23.0-38.9$ & $100.0-208.0$ & $170-240$ & $8.0-10.0$ \\
\hline Muy alto & 5 & $>39.0$ & $>600$ & $>1,000$ & $>10.0$ \\
\hline
\end{tabular}

Fuente: Elaboración propia.

Una vez llegado a este punto, se utilizó el método de tipificación probabilística y el método cartográfico asociado con la asimilación económica del territorio. Vertiente cognoscitiva de la escuela rusa cuyos orígenes se sitúan a inicios de los años setenta del siglo pasado, y que a partir de 1990 se introdujo en los estudios geográficos regionales en México para revelar los desequilibrios socioeconómicos territoriales internos. El procedimiento metodológico que a continuación se describe se desglosa de forma puntual en los trabajos de Propin y Thürner (1986), Propin y Sánchez (1998) y Reyes (1997, 2006).

En primer lugar se procedió a jerarquizar los valores de los indicadores seleccionados en cinco categorías (cuadro 9).

El segundo paso consistió en reemplazar los valores originales, tanto de cada indicador como de cada una de las unidades espaciales de referencia, por la jerarquía correspondiente. Posteriormente se obtuvieron las combinaciones resultantes (cuadro 10).

Después se determinaron las nubes tipológicas que se refieren a grupos de combinaciones, donde el criterio establecido para la asociación de sus elementos consiste en que el comportamiento entre sus indicadores sea lo más similar posible o que sólo difiera en uno o dos valores (figuras I y II).

Lo anterior dio como resultado, para el estado de San Luis Potosí, 11 tipos de territorio según su potencial turístico; ocho de los cuales se manifiestan en la Huasteca Potosina. Cabe mencionar que los municipios que tienen valores muy bajos en sus indicadores no implica que en ellos no se aprovechen adecuadamente sus recursos turísticos, sino que los valores hacen referencia a la concentración de atributos que hacen viable el desarrollo de esta actividad económica.

Para revelar la expresión territorial de los tipos de potencial turístico en la zona de estudio se utilizaron dos métodos cartográficos; uno con- 


\section{Cuadro 10}

\section{Potencial turístico de la región Huasteca Potosina (índices combinados)}

\begin{tabular}{|c|c|c|c|c|c|}
\hline Municipio & Natural & Cultural & Equipamiento & Accesibilidad & Combinación \\
\hline Aquismón & 5 & 2 & 2 & 3 & 5223 \\
\hline Matlapa & 2 & 3 & 2 & 5 & 2325 \\
\hline Tancanhuitz & 2 & 2 & 2 & 4 & 2224 \\
\hline Ciudad Valles & 3 & 3 & 4 & 2 & 3342 \\
\hline Coxcatlán & 1 & 1 & 2 & 5 & 1125 \\
\hline Ébano & 3 & 1 & 2 & 2 & 3122 \\
\hline Huehuetlán & 3 & 2 & 1 & 5 & 3215 \\
\hline San Antonio & 1 & 2 & 1 & 3 & 1213 \\
\hline $\begin{array}{l}\text { San Martín } \\
\text { Chalchicuautla }\end{array}$ & 2 & 2 & 1 & 3 & 2213 \\
\hline $\begin{array}{l}\text { San Vicente } \\
\text { Tancuayalab }\end{array}$ & 1 & 2 & 2 & 5 & 1225 \\
\hline Tamasopo & 4 & 2 & 3 & 2 & 4232 \\
\hline Tamazunchale & 2 & 3 & 2 & 4 & 2324 \\
\hline Tampacan & 1 & 1 & 1 & 4 & 1114 \\
\hline $\begin{array}{l}\text { Tampomolón } \\
\text { Corona }\end{array}$ & 1 & 3 & 1 & 4 & 1314 \\
\hline Tamuín & 2 & 2 & 3 & 2 & 2232 \\
\hline Tanlajás & 2 & 1 & 1 & 3 & 2113 \\
\hline $\begin{array}{l}\text { Tanquián de } \\
\text { Escobedo }\end{array}$ & 2 & 1 & 1 & 4 & 2114 \\
\hline Axtla de Terrazas & 2 & 1 & 2 & 4 & 2124 \\
\hline Xilitla & 2 & 3 & 2 & 3 & 2323 \\
\hline El Naranjo & 2 & 1 & 2 & 2 & 2122 \\
\hline
\end{tabular}

Fuente: Elaboración propia, trabajo de campo.

Figura I

Conformación de nubes tipológicas

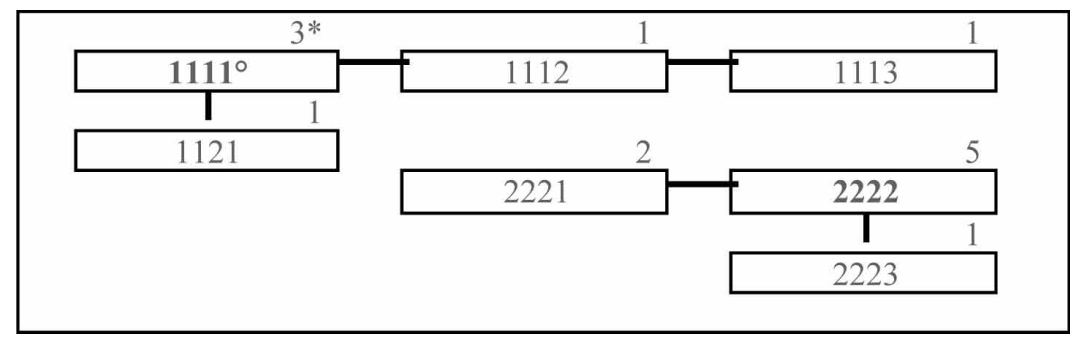

* Consiste en el número de casos con la misma combinación; ${ }^{\circ}$ centro de nube.

Fuente: Reyes, 1997. 


\section{Figura II}

Conformación de nubes tipológicas para el caso de la región Huasteca Potosina*

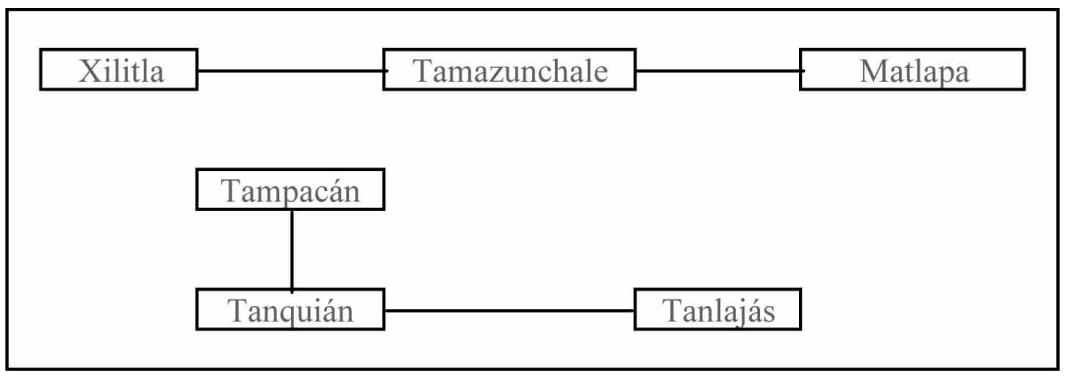

* La correlación entre los demás municipios de la zona de estudio es menos evidente ya que el procedimiento se hizo para todos los municipios que integran la entidad.

Fuente: Elaboración propia.

sistió en la diferenciación cualitativa a través de pantallas, mientras que el segundo implicó el uso del cartograma para aprovechar los límites político-administrativos de los municipios (mapa II).

\section{Resultados obtenidos}

El procedimiento empleado para determinar las cualidades turísticas de los municipios de la Huasteca Potosina, evidencia que para fortalecer el turismo en la región es necesario considerar la arquitectura prehispánica y colonial, las fiestas patronales, las costumbres, las tradiciones y a la propia gente como un patrimonio de similar o mayor importancia que los elementos naturales que de forma preferente se utilizan para su promoción.

En relación con lo anterior, en el mapa II se identifican ocho tipos de territorio de acuerdo con su índice de potencialidad turística. La descripción de cada caso se presenta a continuación.

Tipo i. Lo constituyen los municipios de Huehuetlán, San Antonio, San Martín Chalchicuautla y Tampamolón Corona. En cada uno y en diferente proporción, sólo algunos elementos como auditorios, bibliotecas, zonas arqueológicas (no abiertas al público), monumentos, fiestas patronales y las expresiones culturales de la población indígena, constituyen su patrimonio turístico; en tanto, las cualidades de la base natural y la infraestructura económica están orientadas a otras actividades; por ende, son territorios con las menores posibilidades para avalar los objetivos del Plan Sectorial de Turismo del estado de San Luis Potosí.

Tipo II. La situación anterior cambia ligeramente para los municipios que integran este grupo. Sólo que en este caso, tanto en Coxcatlán como 


\section{Mapa II}

\section{Potencial turístico de la región Huasteca Potosina}

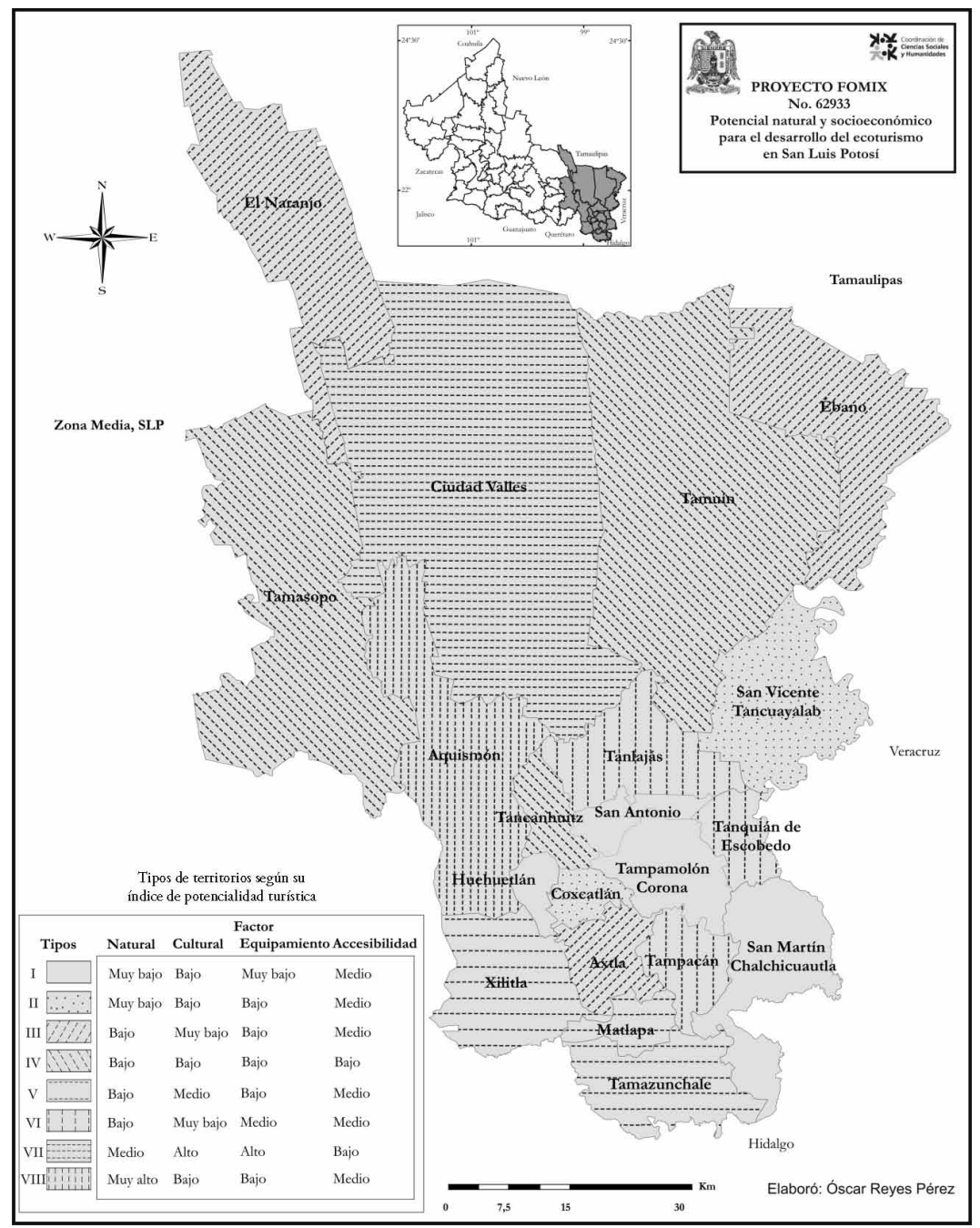

Fuente: INEGI, 2006; trabajo de campo, 2008.

en San Vicente Tancuayalab existe un índice de accesibilidad significativo, y además poseen un incipiente equipamiento turístico.

Tipo III. Aquí el índice de potencialidad turística en los municipios de Ébano, El Naranjo y Axtla de Terrazas se caracteriza por una mayor proporción de atractivos naturales de tipo geomorfológico e hidrológico; mientras que su acervo cultural se restringe básicamente a algunos auditorios, bibliotecas y aspectos culturales de la población indígena. 
Tipo Iv. Incluye los municipios de Tamuín, Tamasopo y Tancanhuitz, cuyos atractivos naturales consisten en cascadas (Tamasopo), lagunas (Poza Azul), ríos (Coy), cavernas (Puente de Dios) y zonas arqueológicas del Preclásico (Tamtok) que han fortalecido la actividad turística en la Huasteca Potosina. Por tanto, si se cuenta con mayor inversión en la creación de equipamiento y servicios turísticos, así como de mejoras en sus condiciones de accesibilidad -siempre susceptible de verse afectada por las condiciones climáticas-, es factible que adquieran la categoría de centros de desarrollo turístico que favorecerían la desconcentración de la economía regional que asume Ciudad Valles.

Tipo v. En este caso, los atractivos naturales de los municipios de Matlapa, Tamazunchale y Xilitla residen en sus ríos (Claro, Amajaque y Tancuilin), manantiales (Tamar), grutas (Xilitla) y vistas panorámicas asociadas con el relieve (La Silleta) o la vegetación (pinos). Pero la mayor parte de sus cualidades turísticas son de corte cultural; a este respecto, en los tres predominan los nahuas como población indígena, por tanto sus costumbres y tradiciones influyen en la elaboración de artesanías y en la celebración de fiestas patronales y religiosas, típicas en el folclor regional. En consecuencia, la potencialidad turística se consolidaría en mayor grado con la apertura al público de las zonas arqueológicas del Preclásico y el Clásico y con la creación de infraestructura para atender al visitante.

Tipo vi. En este grupo los municipios de Tampacan, Tanlajás y Tanquián de Escobedo no cuentan con un patrimonio turístico relevante, ya que en lo natural se remite sólo a algunas lagunas (Chabasaquiche y El Tecolote) y ríos (Choy y Moctezuma); mientras que en lo cultural a auditorios, bibliotecas y expresiones culturales relacionadas con la población teenek. No obstante, al contar con elevados índices de accesibilidad, se constituyen como puntos de enlace hacia los destinos turísticos situados al sur de Ciudad Valles.

Tipo VII. En este caso sólo se incluye a Ciudad Valles, que presenta las mejores condiciones para avalar el programa sectorial de turismo del estado. Su índice de potencialidad turística es producto de la conjunción de sus atractivos naturales y culturales: cascadas (Micos), ríos (Tampaón), balnearios con aguas termales sulfurosas (Taninul y Tamuín), teatros, auditorios, bibliotecas y museos (Regional Huasteco de Arqueología y Antropología) donde se exhiben muestras de la cultura huasteca; también porque es el punto de encuentro y salida para quienes buscan conocer otros centros de ocio y recreación, ya que polariza casi todo el equipamiento turístico de la región; y porque en él convergen las vías de comunicación que lo enlazan con otras entidades del país.

Tipo viII. Por último, el potencial turístico de la región se complementa de forma importante con las cualidades naturales y culturales del 
municipio de Aquismón; ya que además de tener ríos, cascadas, balnearios, grutas y conventos con más de 400 años de antigüedad, cuenta con El Sótano de las Golondrinas, que ha sido declarado una de las maravillas naturales de México. Sin embargo, mientras no tenga un equipamiento turístico que atienda y promueva el regreso de los visitantes, no desempeñará un papel asociativo entre los destinos de ocio y recreación situados de norte a sur en la Huasteca Potosina.

\section{Consideraciones finales}

Desde el punto de vista turístico, la Huasteca Potosina es reconocida en los ámbitos nacional e internacional por la belleza de sus cascadas (Tamul), la majestuosidad de sus grutas (Las Golondrinas) y por la aventura que implica el descenso a través de sus afluentes (río Moctezuma), además de otros atractivos naturales. En contraparte, su acervo cultural consistente en zonas arqueológicas (Tamtok y Tamohi), conjuntos arquitectónicos (iglesia Santiago de los Valles y Castillo de sir Edward James), tradiciones, costumbres y fiestas religiosas derivadas de los grupos indígenas de filiación mesoamericana (nahuas y tének), tiene menos renombre en cuanto a difusión; por ende, también se debe considerar como un elemento prioritario en las estrategias de desarrollo turístico local o municipal.

En este sentido, el procedimiento metodológico utilizado en este trabajo -que ha sido aplicado en otros lugares de México y del mundo por investigadores expertos en el estudio del hecho turístico- hizo posible en primer lugar, mediante una ponderación cuantitativa y cualitativa, integrar variables naturales, culturales y económicas para evaluar la oferta turística y establecer un índice de potencialidad para cada municipio que integra la zona de estudio; después, mediante un procedimiento estadístico (tipificación probabilística) que identifica la repetitividad de indicadores seleccionados en los territorios examinados, agrupó aquéllos que tienen características afines; por último, con el uso de procedimientos cartográficos específicos, se obtuvo un mapa sintético. En suma, la investigación ofrece información significativa para establecer estrategias ad hoc en los lugares donde es viable el desarrollo de la actividad turística.

En relación con lo anterior, el trabajo de campo realizado para el estudio evidenció que aun cuando existe un patrimonio turístico significativo, en esta región no se podrá alcanzar la meta socioeconómica que ha establecido el gobierno del estado a menos que se dé mantenimiento a la infraestructura carretera existente, y que se mejoren sus condiciones cuando no sea posible construir más; que se identifiquen nuevas rutas turísticas o se establezcan nexos entre las que ya se han delimitado; que ante la falta de recursos para nuevos hoteles se abran áreas de campismo 
y de cabañas utilizando materiales de la región; que se generen controles de calidad de los productos que se ofrecen en los establecimientos de alimentos y bebidas; que se incremente la señalización para que los turistas se trasladen a los distintos centros de esparcimiento y que se garantice la seguridad de los visitantes.

En apego con lo que se estipula, es evidente que son numerosas las áreas de trabajo porque la mayoría de los sitios turísticos de la Huasteca Potosina no se aprovechan con fines de ocio y recreación; ya sea por la escasa difusión de sus atractivos, la falta de capacitación para integrar a la población en los empleos derivados de la actividad o por la carencia de infraestructura, además de la inexistencia de planes integrales que definan políticas claras para implementar o fortalecer el turismo, que consideren los problemas sociales, ambientales y la organización territorial de la actividad a partir de un esquema de ordenamiento ecológico.

La complejidad de lo anterior se incrementa porque entre las acciones para incentivar el aprovechamiento de los atractivos naturales y culturales que promuevan los gobiernos municipales y estatal se debe incluir una reglamentación de la actividad turística desde el ámbito local, donde los actores se den a la tarea de elaborar su propia normativa y consideren aspectos socioculturales. Ahora bien, estos instrumentos deberán ser acordes con las tradiciones y costumbres del lugar. En este sentido, el simple hecho de contar con un paraje para obtener recursos económicos no es la única opción para fomentar el turismo, es preciso contar con un respaldo comunitario que se obtendría cuando la población local se considere parte en la toma de decisiones.

Por último, es necesario que los funcionarios de gobierno establezcan canales de comunicación con las comunidades que actualmente aprovechan los recursos turísticos, que den seguimiento a los proyectos que éstas ejecutan y que utilicen su experiencia para abrir nuevos destinos de esparcimiento y descanso.

\section{Bibliografía}

Álvarez, Raúl y Francisco Leno-Cerro (1986), Estudio para la valoración económica y situación estructural del mercado turístico riojano, vol. 3, Instituto de Estudios Turísticos-Gobierno de la Rioja, La Rioja.

Angulo, Adriana, Jorge Sandoval y Marel Hernández (2007), "Herencias territoriales II, 1854-1880: transporte", Nuevo atlas nacional de México, Universidad Nacional Autónoma de México, México, hoja H IV 10. 
Castañeda, Xochizeltzin (2010), "Determinación de áreas naturales prioritarias de conservación con potencial turístico en el estado de San Luis Potosí: una propuesta de sustentabilidad", tesis de licenciatura, Universidad Autónoma de San Luis Potosí, México.

Cruz, Mayra y Adriana Trejo (2007), "Integración del territorio mexicano I. Movimientos sociales", Nuevo atlas nacional de México, Universidad Nacional Autónoma de México, México, hoja H IV 22.

Garza, Gustavo y Cristina Jiménez (2007), "Mapa político-territorial de Mesoamérica hacia 1400", Nuevo atlas nacional de México, Universidad Nacional Autónoma de México, México, hoja H II 1.

Garza, Gustavo, Cristina Jiménez y Rodrigo Tovar (2007), “Mapa político-territorial de Mesoamérica hacia 1520", Nuevo atlas nacional de México, Universidad Nacional Autónoma de México, México, hoja $\mathrm{H}$ II 2.

Gobierno Federal (2009), "Presenta Sectur medidas para reactivar turismo en México", <http://presidencia.gob.mx/prensa/?contenido= 44869>, 22 de octubre de 2010.

INEGI (Instituto Nacional de Estadística, Geografía e Informática) (2002a), Sintesis de información geográfica del estado de San Luis Potosí, INEGI, México.

INEGI (Instituto Nacional de Estadística, Geografía e Informática) (2002b), Sintesis de información geográfica del estado de San Luis Potosí. Anexo cartográfico, INEGI, México.

INEGI (Instituto Nacional de Estadística, Geografía e Informática) (2006), Anuario estadístico del estado de San Luis Potosí, INegi, México.

Jiménez, Cristina (2007), "Integración del territorio I. 1521-1600: avance religioso", Nuevo atlas nacional de México, Universidad Nacional Autónoma de México, México, hoja H II 11.

Leno, Francisco (1993), La evaluación de los recursos turísticos. El caso del Canal de Castilla, t. II, Universidad Complutense, Madrid.

López, Diego (1998), La ordenación y planificación integrada de los recursos territoriales turísticos: estudio práctico de un espacio de "desarro- 
llo turistico incipiente" el Alto Palancia (Castellón), Universitad Jaume I, Castellón.

López, Diego, Juan Bautista-Ferreres y Ouafae Abdelouahab (2009), "Estudio comparado de la potencialidad de los recursos turísticos en los parques de la Sierra Espadán (España) y Talassemtane (Marruecos)", Cuadernos de Turismo, 24, Universidad de Murcia, Murcia, pp. 91-109.

MCD (Ministerio de Cultura y Deportes) (2004), Ley para la Protección del Patrimonio Cultural de la Nación, Dirección General del Patrimonio Cultural y Natural, Ciudad de Guatemala.

Mincetur (2006), "Manual para la formulación del inventario de recursos turísticos a nivel nacional", <http://www.mincetur.gob.pe/turismo/Producto_turistico/Manual_de_Inventario_OCT2006.pdf $>$, 24 de octubre de 2010.

Moyado, Arturo (2007), "Ciclos económicos: consolidación, siglo XviII", Nuevo atlas nacional de México, Universidad Nacional Autónoma de México, México, hoja H III 5.

Olmos, Vianey (2007), "Herencias territoriales, 1742-1810", Nuevo atlas nacional de México, Universidad Nacional Autónoma de México, México, hoja H III 12.

Olmos, Vianey y Lucy Roque (2007a), "Desigualdades regionales, siglo xvi", Nuevo atlas nacional de México, Universidad Nacional Autónoma de México, México, hoja H II 10.

Olmos, Vianey y Lucy Roque (2007b), "Desigualdades regionales, siglos XVII y XVIII", Nuevo atlas nacional de México, Universidad Nacional Autónoma de México, México, hoja H il 4.

Palacio, José Luis, María Teresa Sánchez, José María Casado, Jaime Sancho, Carlos Váldez y Rodolfo Cacho (coords.) (2004), Indicadores para la caracterización y ordenamiento del territorio, Universidad Nacional Autónoma de México-Instituto Nacional de Ecología, México.

Paredes, Carlos (2007), "Desarrollo del poblamiento español", Nuevo atlas nacional de México, Universidad Nacional Autónoma de México, México, hoja H II 4. 
Pinzón, Guadalupe y Flor Trejo (2007), “Organización del territorio novohispano hacia 1789", Nuevo atlas nacional de México, Universidad Nacional Autónoma de México, México, hoja H III 13.

Propin, Enrique y Robert Thürmer (1986), "Un nuevo enfoque metodológico de la regionalización económica en la República de Cuba", Wissenchaftliche Mitteilungen, 18, Institut für Geographie und Geoökologie, Alemania, 5-18.

Propin, Enrique y Álvaro Sánchez (1998), "Niveles de asimilación económica del estado de Guerrero", Investigaciones Geográficas, 37, Universidad Nacional Autónoma de México, México, pp. 59-70.

Reyes, Óscar (1997), "Los niveles de asimilación económica del estado de Puebla", tesis de licenciatura, Universidad Nacional Autónoma de México, México.

Reyes, Óscar (2006), "La evaluación de las condiciones naturales para el desarrollo sustentable de la actividad turística en el estado de Oaxaca”, tesis doctoral, Universidad Nacional Autónoma de México, México.

Reyes, Óscar y Álvaro Sánchez (2005), "Metodología para determinar el potencial de los recursos turísticos naturales en el estado de Oaxaca, México", Cuadernos de Turismo, 16, Universidad de Murcia, Murcia, pp. 153-173.

Sectur (Secretaría de Turismo) (2007), Programa sectorial de turismo 2007 2012, Secretaría de Turismo, México.

Sectur (Secretaría de Turismo) (2009), "Presenta Sectur medidas para reactivar turismo en México", <http://www.sectur.gob.mx/es/ sectur/sect_Boletin_047_Presenta_Sectur_Medidas_para_Reac>, 22 de octubre de 2010.

Sectur (Secretaría de Turismo) (2010a), "Registra actividad turística recuperación para cierre del 2009”, <http://www.sectur.gob.mx/es/ sectur/sect_Boletin_011_Registra_Actividad_Turistica_Recu>, 22 de octubre de 2010.

Sectur (Secretaría de Turismo) (2010b), "Cédula para el registro de patrimonio turístico", <http://www.oaxaca.travel/FOTOS_SIITE/ 
Atractivos/AT0570/PCEDULA\%20PARA\%20EL\%20REGISTRO\%20DE\%20PATRIMONIO\%20TURISTICO2.pdf>, 24 de octubre de 2010.

Stresser-Péan, Guy (2010), "La Huasteca: historia y cultura", Arqueología Mexicana, 14 (79), México, pp. 28-31, <http://www.arqueomex. com/S2N3nHuasteca79.html>, 28 de octubre de 2010.

Vázquez, Valente y Benito Paz (2009), “Turismo y territorio en México: alternativas en el Altiplano Potosino", Biblio 3W, Revista Bibliográfica de Geografía y Ciencias Sociales, XIV (813), 25, Universidad de Barcelona, Barcelona, <http://www.ub.es/geocrit/b3w-813. htm $>, 22$ de noviembre de 2011.

Vázquez, Valente, Óscar Reyes, José Guadalupe Rivera, Miguel Nicolás y Humberto Reyes (2010), "Evaluación de los atractivos naturales para el desarrollo del ecoturismo en la región Huasteca de San Luis Potosí, México", Cuadernos de Turismo, 25, Universidad de Murcia, Murcia, pp. 229-245.

Recibido: 24 de agosto de 2009. Reenviado: 29 de octubre de 2010. Aceptado: 20 de enero de 2011.

Óscar Reyes-Pérez. Es doctor en geografía; profesor-investigador de la Coordinación de Ciencias Sociales y Humanidades (ссьун), de la Universidad Autónoma de San Luis Potosí (UASLP). Forma parte del Sistema Nacional de Investigadores (sNI). Sus líneas de investigación son: geografía del turismo, asimilación económica del territorio y ordenamiento ecológico. En la actualidad tiene a su cargo la dirección del proyecto Propuesta de ordenamiento ecológico de la actividad turística en la costa sur-occidental del Pacífico mexicano con base en la asimilación económica del territorio, auspiciado por sep-Conacyt. Tres de sus últimas publicaciones son: en coautoría, "Evaluación de la inversión pública en materia de cultura en el estado de San Luis Potosí entre 2004 y 2006: un análisis a través de la cartografía", Cuadernos Geográficos, 44, Universidad de Granada, Granada, pp. 151-170 (2009); en coautoría, "Transporte", en Álvaro López y Álvaro Sánchez (coords.), Comarca Lagunera: procesos regionales en el contexto global, UNAM (en prensa) (2009); Actualización programas sectoriales 2004-2009, Comité de Planeación del Desarrollo del 
Estado de San Luis Potosí, San Luis Potosí, a cargo de los programas sectoriales de cultura, educación y juventud (2008).

Valente Vázquez-Solís. Es doctor en geografía; profesor-investigador y coordinador de la licenciatura en geografía de la Coordinación de Ciencias Sociales y Humanidades (CCSyH), de la Universidad Autónoma de San Luis Potosí (UASLP). Forma parte del Sistema Nacional de Investigadores (SNI). Sus líneas de investigación son: regionalización económica, cartografía temática y geografía del turismo. En la actualidad tiene a su cargo la dirección del proyecto Potencial natural y socioeconómico para el desarrollo del ecoturismo en el estado de San Luis Potosí, auspiciado por Fomix-Conacyt. Tres de sus últimas publicaciones son: "Migración internacional, remesas y cambios en la estructura territorial de la economía en el municipio de Cerritos, San Luis Potosí”, Revista Norte Grande, 42, Pontificia Universidad Católica de Chile, Santiago, pp. 5-20 (2009); La regionalización económica del estado de Guerrero, Programa Universitario México Nación Multicultural, Secretaría de Asuntos Indígenas del Estado de Guerrero (en prensa) (2009); en coautoría, "Evaluación de la inversión pública en materia de cultura en el estado de San Luis Potosí entre 2004 y 2006: un análisis a través de la cartografía", Cuadernos Geográficos, 44, Universidad de Granada, Granada, pp. 151-170 (2009).

Humberto Reyes-Hernández. Es doctor en geografía; profesor-investigador de la Coordinación de Ciencias Sociales y Humanidades (ссsун) de la Universidad Autónoma de San Luis Potosí (UASLP), México. Forma parte del Sistema Nacional de Investigadores (SNI), nivel I. Obtuvo su doctorado en geografía ambiental en la Universidad Nacional Autónoma de México (UNAM). Su área de especialización es la percepción remota y los sistemas de información geográficos aplicados al manejo de recursos naturales, impacto ambiental y el desarrollo rural. En 2004 recibió el premio José Antonio Villaseñor y Sánchez a la Investigación Científica y Tecnológica, en el área de ciencias ambientales, que otorga el gobierno del estado de San Luis Potosí. Tres de sus últimas publicaciones son: en coautoría, "Spatial configuration of land-use/land-cover in the Pujal-Coy project area, Huasteca potosina region, Mexico", AMBIO, 37 (5), Royal Swedish Academy of Sciences, Estocolmo, pp. 381-389 (2008); “Cambios en la cubierta vegetal y uso del suelo en el área del proyecto Pujal-Coy, San Luis Potosí, México", Investigaciones Geográficas, 59, unam México, pp. 26-42 (2006); "Los subsidios y apoyos gubernamentales dirigidos al sector agropecuario y la deforestación en Calakmul, Campeche", Investigaciones Geográficas, 51, unam, México, pp. 89-112 (2003). 
Miguel Nicolás-Caretta. Es doctor en arqueología; profesor-investigador y coordinador de la licenciatura en arqueología de la Coordinación de Ciencias Sociales y Humanidades (ссSуH) de la Universidad Autónoma de San Luis Potosí (UASLP). Actualmente dirige el proyecto arqueológico Cerro de Santiago en Aguascalientes. De igual forma participa en proyectos de investigación y docencia en universidades de Europa. Pertenece al Sistema Nacional de Investigadores ( $\mathrm{SNI}$ ) y es autor de varios artículos y libros relacionados con la arqueología. Tres de sus últimas publicaciones son: "Archaeology and Physical Anthropology: A reflection on warfare in the archaeological vision", en Maxine E. McBrinn y Laurie D. Webster (eds.), Archaeology without Borders Contact, Commerce, and Change in the U.S. Southwest and Northwestern Mexico, University of Colorado Press-INAH, Boulder, pp. 385-392 (2008); "Desarrollo social precolombino en el Norte de México", en A. Irisarri, Alexander Betancourt Mendieta y M. Nicolás Caretta (coords.), Estudios regionales y de fronteras interiores, UASLPMiguel Ángel Porrúa, México, pp. 9-20 (2008); "Retrospectiva sobre los cazadores", en Carlos Alberto Casas y María Helena Ortolan (coords.), Miradas histórico-antropológicas sobre las fronteras interiores en América Latina, Miguel Ángel Porrúa-Ufam, México, pp. 225-239 (2010).

José Guadalupe Rivera-González. Es doctor en ciencias antropológicas; profesor-investigador y coordinador de la licenciatura en antropología de la Coordinación de Ciencias Sociales y Humanidades (ccsyH) de la Universidad Autónoma de San Luis Potosí (UASLP). Forma parte del Sistema Nacional de Investigadores (SNI). Sus líneas de investigación son: antropología política, administración y uso del patrimonio cultural, y antropología del trabajo y la familia. Dirigió el desarrollo del proyecto Antropología e industria. Un estudio antropológico en torno al impacto socioeconómico y cultural del sector manufacturero automotriz en el municipio de San Luis Potosí, auspiciado por SEP-Promep. Entre sus publicaciones sobresalen: Actualización programas sectoriales 2004-2009, Comité de Planeación del Desarrollo del Estado de San Luis Potosí, a cargo de los programas sectoriales combate a la pobreza, asistencia social y salud (2008); "La globalización de la tierra nómada: las fronteras económicas desbordadas en San Luis Potosí y su impacto sociocultural", en Ana Irisarri Aguirre, Alexander Betancourt Mendieta y M. Nicolás Caretta (coords.), Estudios regionales y de fronteras interiores, UASLP-Miguel Ángel Porrúa, México, pp. 153-182 (2008); "Reabriendo fronteras: la inversión extranjera en San Luis Potosí (1998-2005)”, Universitarios Potosinos, UASLP, nueva época, año 2, 4, pp. 38-41 (2006). 